\title{
Impact of Health Education on Awareness of Sedentary Lifestyle as Predisposing Factor to Cardiovascular Diseases among Secondary School Principals in Zone 4 Nigeria
}

\author{
Adetoun Tayewo Akinwusi*, Olusola Jacob Odelola \\ Department of Human Kinetics and Health Education, University of Ibadan, Ibadan, Nigeria
}

Copyright $@ 2018$ by authors, all rights reserved. Authors agree that this article remains permanently open access under the terms of the Creative Commons Attribution License 4.0 International License

\begin{abstract}
Skeletal muscles contract to produce body movement. Essentially, skeletal muscle activities affect the health of other organs such as heart, adipose tissue, brain. Engaging in physical exercise enhances proper functioning of body organs, thus promoting healthy living. Nigerian secondary school principals are not known to engage in physical exercise, probably due to poor awareness of its importance to their health. Meanwhile, a life of inactivity otherwise called sedentary lifestyle is a risk factor to cardiovascular disease. In recent times, cardiovascular disease has led to a significant increase in deaths among administrators in Nigeria. Therefore, this study examined impact of Health Education on awareness of sedentary life style as predisposing factor to cardiovascular diseases among secondary school principals in zone 4, Oyo State, Nigeria. The study adopted a single group pre-test-post-test quasi experimental research design. Participants were given Health education on sedentary lifestyle and related diseases as its resultant effect. A split plot analysis of variance (SPANOVA) was employed to find the difference in pre-test-post-test scores of the participants. The result showed that, health education given was effective. The participants' awareness level increased, thus willing to refrain from sedentary lifestyle and adopt a sporting lifestyle. It was recommended that, the Ministry of Education should mandate school managements to create time during the school hours for principals and members of staff to engage in physical exercises. Also, health education in which disease prevention will feature prominently should form part of the agenda during meetings of school principals.
\end{abstract}

Keywords Awareness, Cardiovascular Diseases, Predisposing Factors, Sedentary Life, School Principals

\section{Introduction}

Movement is integral to human existence because it is an important characteristic of every living organism. Human body movement which results from the contraction of skeletal muscle is called physical activity. Physical activity is important for maintaining appropriate body weight, healthy body density, muscle strength, joint mobility, physiological well-being as well as reducing surgical risks and strengthening of the immune system. Myers (2003) stated that, regular exercise has a favourable effect on many of the established risk factors by promoting weight reduction, reducing blood pressure, reducing "bad" cholesterol (low-density lipoprotein - LDL) level in the blood as well as total cholesterol and raising the "good" cholesterol ( high-density lipoprotein - HDL) level.

Exercise programme can be categorized into anaerobic and aerobic. Anaerobic exercise is the exercise in which activity is performed without using oxygen. Sprinting is an example of anaerobic exercise. Aerobic exercises are those activities performed using large quantities of oxygen for most of the time. Examples of aerobic exercises are walking, running, skipping, jogging, calisthenics and dancing. Aerobic exercise training programme can result in modest decrease in body weight and body fat storage, blood pressure (particularly in persons with elevated resting blood pressure), total blood cholesterol, serum triglycerides, and low-density lipoprotein cholesterol as well as increase in the protective high density lipoprotein cholesterol sub fraction (Franklin, Balady, Berra, Gordon \& Pollock, 2014).

A sedentary lifestyle is when a person does not exercise on regular basis and is minimally active during the course of a regular day (Chris, 2017). A sedentary behaviour such as the amount of time spent watching television, using a computer, or playing video games is associated with 
obesity, metabolic syndrome and type 2 diabetes mellitus, all of which increase the risk of developing coronary heart diseases (CHDs) and cardiovascular diseases (CVDs) (Shiroma \& Lee, 2010).

World Health Organisation (WHO, 2008) estimated that more than 17.3 million people (males and females) die of cardiovascular diseases (CVDs) such as heart attack and stroke. However, $80 \%$ of premature heart attacks are preventable through consumption of healthy diets, physical activity and non-use of tobacco. Healthy diet is the one that include; fruits and vegetables, whole grains, lean meats and fish.

Principals are head teachers in secondary schools who are at the peak of their career. They rarely teach in classrooms but rather engaged in administrative work, thus making them vulnerable to sedentary lifestyle. Age is a moderating variable in this study. Arteries stiffen with age thereby contributing to the likelihood of increased occurrence of cardio-vascular disease in older people. Also, adherence to exercise regimen tends to reduce with increase in age.

In this study, health education was carried out among principals of secondary schools. This is with a view to increasing their awareness level about sedentary lifestyle as predisposing factor to cardiovascular disease. The training package used is on awareness of sedentary lifestyle as predisposing factor to cardiovascular diseases. According to Nazil and Umit, (2005) health education is one of the tools to provide individual with knowledge, skills and motivation to make healthier lifestyle choices especially when properly targeted.

The study is based on health belief model. The underlying concept of the model is that health behaviour is determined by personal beliefs or perceptions about a disease and the strategies available to decrease it occurrence (Tuner, Hunt, Dibrezzo and Jones, 2004). The model addresses four major constructs for compliance with recommended action namely; perceived susceptibility to the disease and perceived severity, perceived benefits, perceived barriers to recommended action (Groubadia, 2015). In the context of this study the first objective was to bring the attention of the principals to a disease (cardiovascular disease) that they are susceptible to, the second was to let the individual know that the disease was severe, the third was to let the people know what they stand to benefit if certain recommended action (exercise) is taken and the fourth was to let the individual know that there are barriers (e.g. age) that can prevent them from taking such recommended actions that are beneficial to them. This model is appropriate because this study sought to provide health education which is in form of health literacy in order to help increase the participants awareness level on sedentary lifestyle as predisposing factor to cardiovascular diseases, encourage change of attitude and adopt sporting lifestyle.

\section{Statement of the Problem}

It is worrisome that developing countries are presently carrying larger burden of cardiovascular diseases and the likelihood that the trend may continue in an increased manner generates anxiety. World Health Organisation in 1996 estimated that, in 1990 there were already twice as many deaths and more than three times as many Disability-Adjusted life years (DALYs) attributable to CVDs in developing countries, in addition, by year 2020, there will be about 6 million deaths and 35 million DALYs annually from cardiovascular causes in developed countries and about 19 million deaths and 170 million DALYs annually from cardiovascular causes in developing countries (Oguanobi et al, 2013). Cardiovascular disease is one of the major causes of disability and death among adult population in Nigeria. Akintunde, Salawu \& Opadipo (2014) in a study carried out in Nigeria found that, age groups 36 years- 45 years and 46 years-60 years were particularly affected by the burden of cardio-vascular risk factors. The school principals who are the target population for this study fall into these age categories. According to Kavanagh \& Draper (2011) taking up exercise to prevent cardiovascular disease, or to reduce its risk of occurrence in those already affected by it, is efficacious and not associated with any appreciable harmful effects if performed with appropriate safeguards. Despite the recommendation of WHO (2003) that, the individual should do 30 minutes or more of moderate intensity exercise at least 4 to 5 days a week to obtain multiple health benefits, the target population do not participate in exercise for improved health status, perhaps due to their poor awareness level. Health education is a field of study that creates awareness thereby stimulating knowledge for attitude change and eventual positive health behaviour. Previous studies examined health benefits of exercise. This study examined experimentally, impact of health education on awareness of sedentary lifestyle as predisposing factor to cardiovascular diseases among secondary school principals in zone 4, Nigeria The objective of this study was to investigate the effects of Health Education Intervention on awareness of sedentary lifestyle as a predisposing factor to cardiovascular diseases among secondary school principals in Zone 4, Nigeria. Also, moderating influence of age of participants on awareness of sedentary lifestyles as a predisposing factor to cardiovascular diseases was examined.

\section{Hypotheses}

The following hypotheses were tested:

\section{Hypothesis One}

There will be no significant difference in the pre-test and post-test scores on awareness of sedentary lifestyle as a predisposing factor to cardiovascular diseases among secondary school principals following an eight weeks 
Health Education Intervention

\section{Hypothesis Two}

Age will not significantly moderate the difference that exists in the pre-test and post-test scores of participants on awareness of sedentary lifestyle as a predisposing factor to cardiovascular diseases.

\section{Methodology}

\section{Research Design}

Single group pre-test and post-test quasi experimental research design was used and questionnaire was administered to the participants (pre-test).Eight weeks health education programme was conducted and the same set of questionnaire was administered (post-test) to the participants after the intervention.

\section{Population of the Study}

Participants for the study comprised all principals in zone 4 Nigeria.

\section{Sample and Sampling Technique}

The study made use of fifty-four principals that volunteered to participate in the study

\section{Research Instrument}

A self-developed questionnaire structured according to the hypotheses tested was the instrument for the study. It was a 4-point modified Likert format using Strongly Agree (4), Agree (3), Disagree (2) and Strongly Disagree (1). The questionnaire was validated by experts in the field of health education.

\section{Validity of the Instrument}

The health education package and awareness questionnaire were vetted by three Health Education experts in the Department of Human Kinetics and Health Education, University of Ibadan to establish face and content validity of the instruments. On the basis of the suggestions made by these experts, the instruments were reconstructed where necessary.

\section{Reliability of the Instrument}

In order to establish reliability of the instrument, a pilot study was conducted. 20 respondents randomly selected from other zones were used as the population. The data collected were statistically analysed to determine the reliability coefficient of the item. The coefficient was found to be 0.83 using test-retest method. Thus, the questionnaire was reliable for the purpose of the study.

\section{Method of Data Collection}

Questionnaire items were administered pre and post intervention. On the spot collection was done using four research assistants.

\section{Procedure for Treatment}

A letter was written to Association of Nigeria Conference of Principals of Secondary Schools Oyo State zone 4 to obtain permission in order to conduct the research. The venue used for the intervention was visited before the commencement of the study to familiarise with the environment. The principals used as sample were served consent forms to indicate their willingness to participate in the study. The researchers with the assistance of four people held 35 minutes session for the experimental group for eight weeks.

The intervention sessions are briefed below:

- Session I: Pre-test administration and general orientation on health and health education.

- Session II: Definition of cardiovascular disease and explanation of the types.

- Session III: Risk factors of cardiovascular diseases: lack of exercise, unhealthy eating, stress, diabetes, high blood pressure, high cholesterol and smoking.

- Session IV: Meaning of sedentary lifestyle and explanation on how it causes cardiovascular diseases.

- Session V: Explanation on mechanism of anti-cardiovascular disease effect of exercise: structural adaptations, renin-angiotensin system and vascular responsiveness.

- Session VI: Specific exercises to prevent cardio-vascular disease.

- $\quad$ Session VII: Exercise devices for cardio-vascular disease prevention at different age ranges.

- $\quad$ Session VIII: Revision of activities in the previous sessions and administration of questionnaire to collect post-test scores.

\section{Method of Data Analysis}

Split Plot Analysis of Variance (SPANOVA) was employed to analyse the differences in the pre-test and post-test scores of the participants. 


\section{Results}

\section{Ho1: There will be no significant difference in the pre-test and post-test scores of participants on awareness of sedentary lifestyle as predisposing factor to cardiovascular diseases.}

Table 1. Paired T-test showing difference in pre-test and post-test scores on awareness of sedentary lifestyle as predisposing factor to cardiovascular diseases

\begin{tabular}{|c|c|c|c|c|c|c|c|c|}
\hline Variable & Time & $\mathrm{N}$ & Mean & Std. Dev & $\mathrm{Df}$ & t-value & $\mathrm{P}$ & Remark \\
\hline \multirow{2}{*}{ Awareness } & $\begin{array}{l}\text { Pre-test } \\
\text { Score }\end{array}$ & 54 & 13.7481 & 5.39155 & \multirow{2}{*}{53} & \multirow{2}{*}{3.837} & \multirow{2}{*}{$<.001$} & \multirow{2}{*}{$\begin{array}{c}\text { Ho1 } \\
\text { Rejected }\end{array}$} \\
\hline & $\begin{array}{l}\text { Post-test } \\
\text { Score }\end{array}$ & 54 & 17.0833 & 2.75707 & & & & \\
\hline
\end{tabular}

Table 1 reveals that, there was a significant difference in the pre-test score (mean=13.7481) and post-test score (mean=17.0833) of participants' on awareness of sedentary lifestyle as predisposing factor to cardiovascular disease; $\mathrm{t}(53)=3.837, \mathrm{p}<.001$. Hence, null hypothesis was rejected.

\section{Ho2: Age will not significantly moderate the differences that exist in the pre-test and post-test scores of participants on awareness of sedentary lifestyle as predisposing factor to cardiovascular diseases.}

To achieve this, Split Plot Analysis of Variance (SPANOVA) was employed to examine the differences in pre-test and post-test scores of participants on awareness of sedentary lifestyle as predisposing factor to cardiovascular diseases with respect to age range.

Table 2. SPANOVA showing difference in participants' awareness level on sedentary lifestyle as predisposing factor to cardiovascular diseases in relation to time (pre-test and post-test) and age

\begin{tabular}{|c|c|c|c|c|c|c|c|}
\hline \multicolumn{2}{|c|}{ Effect } & Value & F & Hypothesis df & Error df & Sig. & Partial Eta Squared \\
\hline \multirow{4}{*}{ Time } & Pillai's Trace & .647 & $95.396^{\mathrm{a}}$ & 1.000 & 52.000 & .000 & .647 \\
\hline & Wilks' Lambda & .353 & $95.396^{\mathrm{a}}$ & 1.000 & 52.000 & .000 & .647 \\
\hline & Hotelling's Trace & 1.835 & $95.396^{\mathrm{a}}$ & 1.000 & 52.000 & .000 & .647 \\
\hline & Roy's Largest Root & 1.835 & $95.396^{\mathrm{a}}$ & 1.000 & 52.000 & .000 & .647 \\
\hline \multirow{4}{*}{ time * Age } & Pillai's Trace & .749 & $155.369^{\mathrm{a}}$ & 1.000 & 52.000 & .000 & .749 \\
\hline & Wilks' Lambda & .251 & $155.369^{\mathrm{a}}$ & 1.000 & 52.000 & .000 & .749 \\
\hline & Hotelling's Trace & 2.988 & $155.369^{\mathrm{a}}$ & 1.000 & 52.000 & .000 & .749 \\
\hline & Roy's Largest Root & 2.988 & $155.369^{\mathrm{a}}$ & 1.000 & 52.000 & .000 & .749 \\
\hline
\end{tabular}

Table 2 reveals that, there was a significant interactive effect of time and age on participants awareness level on sedentary lifestyle as predisposing factor to cardiovascular diseases; Wilks’ Lambda $=0.251, \mathrm{~F}_{(1,52)}=155.369, \mathrm{p}<.001$. Hence null hypothesis was rejected. This implies that, age moderated the difference that exists in pre-test and post-test scores of participants' level of awareness about sedentary lifestyle as predisposing factor to cardiovascular diseases. The table further shows that, age of participants accounted for 74.9\% (Partial Eta Squared $=0.749$ ) variance in participants' level of awareness. The age of participants had significant effect on their posttest scores.

Table 3. Showing sedentary lifestyle differences of participants in different age range

\begin{tabular}{|c|c|c|c|c|c|c|}
\hline Source & Type III Sum of Squares & Df & Mean Square & F & Sig. & Partial Eta Squared \\
\hline Intercept & 23512.022 & 1 & 23512.022 & 3279.686 & .000 & .984 \\
\hline Age & 489.656 & 1 & 489.656 & 68.302 & .000 & .568 \\
\hline Error & 372.787 & 52 & 7.169 & & & \\
\hline
\end{tabular}

Table three reveals that, there was significant difference on sedentary lifestyle of principals at different age ranges; $\mathrm{F}_{(1,52)}=68.302, \mathrm{p}<.001$. Age difference accounted for $56.8 \%$ of variance in participants' sedentary lifestyle post-test scores. To further understand the nature of differences that exist in the sedentary lifestyle of participants with different age range, pair wise comparison (Bonferoni) was computed. 
Table 4. Pair wise Comparison (Bonferroni) showing nature of differences that exist in the sedentary lifestyle of the participants with different age-range

\begin{tabular}{|c|c|c|c|c|}
\hline (I) Age range & Mean & Mean Difference (I-J) & Std. Error & Sig. $^{\text {a }}$ \\
\hline 41-50 years & 12.848 & $4.334^{*}$ & .524 & .000 \\
\hline 51-60 years & 17.181 & $4.334^{*}$ & .524 & .000 \\
\hline
\end{tabular}

Table 4 reveals that, partcipants within the age range of 51-60 years (mean=17.181) displayed higher tendency to indulge in sedentary lifestyle than those within the agerange 41-51 years (mean=12.848). This implies that, older principals were more prone to sedentary lifestyle than younger ones.

\section{Discussion}

The finding of this study shows that, health education intervention had significant positive effect on awareness level of secondary school principals regarding sedentary lifestyle as predisposing factor to cardiovascular diseases. They were willing to engage in more physical activities in order to reduce the risk of cardio-vascular diseases after the intervention. This finding is quite in agreement with the submission of World Health Organisation (WHO) (2013) that, health education interventions are effective at increasing the awareness of disease and care-seeking behaviour in populations with Acute Rheumatic fever (ARF) and Rheumatic Heart Disease (RHD). In the opinion of Ramsey, Walkins \& Engel (2013), health education helps to empower people to take responsibility for their own well-being by gaining control over the underlying factors that influence health. Also, Alzaman, Wartak, Friderici \& Rothberg (2013) examined in a study, the association between awareness of risk factors and ideal cardiovascular health behaviour, the result showed that, awareness was positively associated with healthy behaviour in the following multivariable models; obesity, hypertension, exercise, cholesterol and diabetes. Health education is the most effective approach to disease prevention.

This study also found that, principals within the agerange of 51years to 60 years displayed higher tendency to indulge in sedentary lifestyle more than other age group. The finding is in agreement with the submission of Iversen (2010) that, with advancing age, adherence to exercise diminishes and is lower still among older adults with arthritis.

\section{Conclusions}

Health education given to participants had a significant effect on their awareness about sedentary lifestyle as predisposing factor to cardiovascular diseases. Physical activity is the most effective strategy for the prevention of cardio-vascular diseases.

\section{Implications of the Study}

In this study, health education given as intervention was effective in enhancing the awareness of sedentary lifestyle as predisposing factor to cardiovascular diseases among secondary school principals. This points to the fact that, awareness of diseases prevention strategy is important to its adherence. Also, health education is a potent awareness creation approach on health related issues. The much needed improved health status of Nigerian for national development can be achieved through investment in preventive aspect of health system.

\section{Recommendations}

It is important that, the school principals participate in physical activities for healthy living. It is along this line that the following recommendations were made:

1. Government at all levels should make adequate provision for human and material resources for the implementation of Physical Education programme in schools.

2. Ministry of Education at federal level should make it mandatory for school principals and teachers to devote some time during the school hours to participate in physical exercise.

3. Health Education in which disease prevention will feature prominently should form part of the programme of school principals during their meetings.

4. Health education programme on awareness creation as regards cardio-vascular diseases prevention should be made to feature in print and electronic media in order to benefit the general public.

5. In planning exercise programme for disease prevention, age must be taken into consideration.

\section{REFERENCES}

[1] Akintude, A.A., Salawu, A.A. \& Opadijo, O.G. (2014).Prevalence of traditional cardiovascular risk factors among staff of Ladoke Akintola University of Technology, Ogbomoso, Nigeria. Nigerian Journal of Clinical Practice. Accessed from http://www.njcponline.com/article.asp? on 04-04-2014

[2] Alzaman N., Wartak, S.A. Friderici, J.\& Rothberg, M.B. (2013).Effect of patients' awareness of cardiovascular Disease risk factor on health-related behaviour. Accessed from http://www.ncbi.nlm.nih.gov/pubmed/24192 on 04-04-2016

[3] Chris,l, (2017). Definition of a sendentary from lifestyle. Accessed from www.healthhype.com on 07-09-2017 
[4] Franklin, B.A., Balady, M.D., Barra, K., Gordon, N.F., \& Pollock (2014). Exercise for persons with cardiovascular Disease. American College of Sports Medicare Accessed www.acsm.org on 07-04-2014.

[5] Iversen, M.D. (2010). Physical Therapy for Older Adults with Arthritis: What is Recommended? International Journal of Clinical Rheumatol 5(1): 37-51: 37-51. Accessed from http://www.medscape.com/viewarticle/721536_10 20-05-2015

[6] Guobadia, E.A. ( 2015).The effects of a sickle cell disease education intervention among college students. Olden University. Retrieved from http://scholarworks.walden.edu/dissertation.on 07-01-2017

[7] Kavanagh A \& Draper C (2011).Physical exercise and vascular risk. Accessed from http://www.patient.co.uk/doctor/heart-Disease-and-exercise on $07-3-2014$.

[8] Myers, J. 2006. Exercise and Cardiovascular Health. Accessed from http://circahajournalsorg/content/107/1/02.ful on 04 06-2014.

[9] Nazil, A. \& Umit, A.A. (2005). Pilot Project to develop and assess health education programme for type 2 diabetes mellitus patients. Health Education Journal 64 (3): 339-346. Retrieved from http://www.researchgate.net/publication/25/230978_A_pilo t. on $07-01-2017$
[10] Oguanobi N I ., Ejim E C, Onwuebere B.J., lke,S O, Anisiuba B C., Ikeh V .O. \& Aneke E. O. (2013) Pattern of cardiovascular disease amongst medical admissions in a regional Teaching Hospital in Southeastern Nigeria. Nigeria Journal of Cardiol.10:77-80.

[11] Ramsey, L.S., Watkins L. \& Engel M.E. (2013). Health education interventions to raise awareness of rheumatic fever: a systemic review protocol. Accessed from http://www.ncbi.nlm.nih.gov/pmc/article/PMC3705751 on 20-05-2015.

[12] Shiroma, E.J. \& Lee, Min (2010). Exercise in Cardiovascular Disease. Accessed from htt://cir.ahajournals.org on 21-05-2016.

[13] Tuner, L.W., Hunt, S.B., Dibrezzo, R. \& Jones C. (2004) Design and Implementation of an Osteoporosis Prevention programme using the health belief model. American Journal of Health Studies 19 (2) 115-121.

[14] World Health Organisation (WHO)(2003). Economic benefits of physical activity: Non-communicable disease prevention and Health promotion. Accessed from http:wwww.who.int.hpr/physactiv/economic.benefits.shtml on $07-08-2010$

[15] WHO (2008). The Global burden of disease: 2004 Update. Geneva

[16] WHO (2013).The Ottawa Charter for Health Promotion. Accessed from http://.www.who.int/healthpromotion/conference/previous/ ottawa/en on 02-03-2014. 